\title{
Injury risk functions for the four primary knee ligaments
}

\author{
Corresponding author: \\ Jiota Nusia \\ Department of Traffic Safety and Traffic System, Swedish National Road and Transport Research \\ Institute (VTI), Stockholm, Sweden. \\ jiota.nusia@vti.se
}

\section{Co-authors:}

\section{Jia Cheng Xu}

Department of Traffic Safety and Traffic System, Swedish National Road and Transport Research Institute (VTI), Stockholm, Sweden.

\section{Reimert Sjöblom}

Department of Strength and Crash Analysis (RCCC), Scania CV AB, Södertälje, Sweden.

\section{Johan Knälmann}

Department of Strength and Crash Analysis (RCCC), Scania CV AB, Södertälje, Sweden.

\section{Astrid Linder}

Department of Traffic Safety and Traffic System, Swedish National Road and Transport Research Institute (VTI), Gothenburg, Sweden.

Department of Applied Mechanics, Chalmers University of Technology, Gothenburg, Sweden.

\section{Svein Kleiven}

Department of Biomedical Engineering and Health Systems, KTH Royal Institute of Technology, Stockholm, Sweden. 


\section{ABSTRACT}

Aim: The purpose of this study was to develop Injury Risk Functions (IRFs) for the Anteriorand Posterior Cruciate Ligament ( $\mathrm{ACL}$ and $\mathrm{PCL}$, respectively) and the Medial- and Lateral Collateral Ligament ( $M C L$ and $L C L$, respectively) in the knee joint and address two injury mechanisms of the ligaments, mid-substance failure and ligament insertion detachment.

Method: The IRFs were developed from Post-Mortem Human Subject (PMHS) tensile failure strains of Bone-Ligament-Bone (BLB) or dissected Ligament (LIG) preparations. To compensate for insufficient sample size of experimental datapoints, virtual failure strains were as well generated based on mean- and standard deviation from experiments that did not provide specimen-specific results. All virtual and specimen-specific values were then categorised into groups of static and dynamic rates and tested for the best fitting theoretical distribution to formulate the ligament IRF. Results: Nine IRFs were derived ( 3 for ACL, 2 for $\mathrm{PCL}, 1$ for MCL and 3 for LCL). Conclusion: These IRFs are, to the best of the authors' knowledge, the first knee ligament injury predicting tool based on PMHS data. The IRFs of BLB address both failure modes of mid-ligament and attachment failure, while the IRFs of LIG address mid-ligament failures only. The proposed risk functions can be used to determine the effectiveness of injury prevention measures. Keywords: Injury risk functions, knee ligaments, anterior cruciate ligament, posterior cruciate ligament, medial collateral ligament, lateral collateral ligament.

\section{KEYWORDS}

Injury risk functions, knee ligaments, anterior cruciate ligament, posterior cruciate ligament, medial collateral ligament, lateral collateral ligament. 


\section{INTRODUCTION}

Knee ligament injuries are associated with both low-energy- and high-energy trauma[1]. Traffic as well as sports related accidents (high- and low-energy trauma, respectively) are two main causes of Anterior- and Posterior Cruciate Ligament injuries ( $\mathrm{ACL}$ and PCL, respectively) leading to primary reconstructions, both as single injuries as well as multiligament injuries[2-5]. Although not life-threatening, knee ligament injuries increase the risks of subsequent injuries such as arthritis, meniscus tear and the need for a total knee replacement[6-9], reduces the possibility of returning to previous levels of sporting activity $[8,10,11]$ and can have a long-term negative effect on the quality of life[12,13].

The four primary knee ligaments; ACL, PCL and the Medial- and Lateral Collateral Ligaments ( $M C L$ and $L C L$, respectively), are commonly associated with three different injury mechanisms: (1) Mid-section failure is a rupture within the ligament itself; (2) Ligament detachment occurs at the interface between the ligament and the bone, and; (3) Avulsion fractures occur when osseous fragments adjacent to the ligament insertion sites follows as the ligaments detaches[14-21]. These three different failure modes are a consequence of the interaction between ligament and bone, which have substantially different mechanical properties.

Evaluating the risk for injury can be done using numerical simulations. Mathematical models, such as Human Body Models (HBMs), are expected to gradually and to a larger extent complement experiments using physical dummies. HBMs offers the opportunity to evaluate impacts down to tissue level and address occupant diversity to a greater extent than what is practically possible using physical dummies. Local Injury Risk Functions (IRFs) are needed in the evaluation of the knee ligament responses as they predict the risk of injury on a material level, allowing injury mechanisms to be accounted for. Existing IRFs for the lower extremities have primarily been focusing on skeletal fractures[22-27]. These functions describe the global injury risk of the Knee-Thigh-Hip (KTH) complex[22-25], however, they do not address the knee ligament responses as they assume injury risk based only on fracture loads. Knee ligament injuries are dependent on impact location and the IRFs herein might underestimate the risk for KTH injury, by not being sensitive enough to capture knee ligament injuries caused by impact loads below fracture magnitudes[24].

The objective of this study is to create local IRFs for the four primary knee ligaments: ACL, $P C L, M C L$ and $L C L$. The IRFs are aimed at addressing ligament tissue failure on mid-substance and ligament detachment at the insertion site, excluding avulsion involving bony fractures. 


\section{METHOD}

Cumulative injury risk functions were derived from specimen-specific results in experimental studies conducted on Post-Mortem Human Subject (PMHS) ligaments. However, only a limited number of individual strain results for each tested specimen were found in literature, insufficient to alone construct IRFs. To cover for the lacking specimen-specific results, virtual failure strains were statistically generated from the articles that only provided results as mean- and Standard Deviation (SD).

\section{Study search}

A literature search was performed for experimental studies conducting uniaxial failure tests on PMHS ligaments. The search was conducted iteratively between February 2019 and April 2021, mainly on Google Scholar. Some of the search words used include "ACL/PCL/MCL/LCL material properties", "Failure strain", "Tensile properties", "Knee joint" in different combinations. Most of the collected studies shown in Table A1 in Appendix A, were found by reviewing the reference list in articles generated by the Google Scholar search.

\section{Study selection}

The inclusion criteria for selecting a study in the development of injury risk functions were: (1) Ligament failure (deformation at maximum load) had to be presented in terms of strain values, or elongation failures together with initial ligament lengths; (2) conducted on adult PMHS, and; (3) Primary sources of the experiment results, exclusively. Results stating bony fracture or avulsion as failure mode were excluded as they do not represent an injury mechanism on the ligament tissue itself. Table 1 lists all studies meeting these criteria.

Four of these articles provided specimen-specific failure strains[18, 28-30]. Wilson et al.[31] presented failure elongation for each LCL specimen; however, the initial lengths were given as an average. Virtual failure strains were therefore statistically generated from a presented mean failure strain. Van Dommelen et al.[32] included the results of Kerrigan et al.[29] in the averaging of LCL failure strains. Hence, to avoid duplication of data, the reported LCL results in Kerrigan et al.[29] were not applied. Further, van Dommelen et al.[32] results for MCL were excluded from the current study as the authors' reported that they had used inaccurate initial MCL length in the failure strain calculation. Paschos et al.[18] strain results at maximum tensile load were extracted from the force-elongation graphs using the online tool WebPlotDigitizer[33]. 
bioRxiv preprint doi: https://doi.org/10.1101/2021.07.30.454445; this version posted August 1 , 2021. The copyright holder for this preprint (which was not certified by peer review) is the author/funder. All rights reserved. No reuse allowed without permission.

Original research

Injury risk functions for the four primary knee ligaments

Jiota Nusia

TABLE 1. Mean failure strains $\pm S D$ as reported by studies used to construct the injury risk functions. The uniaxial tensile tests were conducted on either Bone-Ligament-Bone (BLB) specimens or dissected Ligaments (LIG). The studies are grouped according to dynamic (red) or static (green) tensile rate. " $N$ " represents the number of specimens used in the averaging while "Failure mode" specifies the injury mechanisms of the BLB specimens; (1) Mid-substance ligament failure, or (2) Failure at ligament attachment site. Empty boxes indicate that the information was not presented.

*Specimen-specific results provided.

\begin{tabular}{|c|c|c|c|c|c|c|}
\hline Study & $\begin{array}{c}\text { Mean } \\
\text { strain } \\
{[\%]}\end{array}$ & $\begin{array}{l}\text { SD } \\
{[\%]}\end{array}$ & $\mathbf{N}$ & Tensile rate & Specimen & Failure mode \\
\hline \multicolumn{7}{|c|}{ ANTERIOR CRUCIATE LIGAMENT } \\
\hline Butler et al. [28] - AMB* & 19.1 & 2.8 & 5 & $100 \% / s$ & BLB & Ligament \& insertion site \\
\hline Butler et al. [28]- ALB* & 16.1 & 3.9 & 6 & $100 \% / s$ & BLB & Ligament \& insertion site \\
\hline Butler et al. [28] - PC* & 15.2 & 5.2 & 6 & $100 \% / s$ & BLB & Ligament \& insertion site \\
\hline Chandrashekar et al. [37] - Male & 30.0 & 6.0 & 8 & $100 \% / s$ & BLB & Ligament failure \\
\hline Chandrashekar et al. [37] - Female & 27.0 & 8.0 & 9 & $100 \% / s$ & BLB & Ligament failure \\
\hline Nooyes \& Grood[17] - Younger & 44.3 & 8.5 & 6 & $100 \% / s$ & BLB & Ligament failure \\
\hline Van Dommelen et al.[32] - aACL & 18.0 & 2.8 & 4 & $54 \pm 9.2 \% / s$ & BLB & Ligament failure \\
\hline Van Dommelen et al.[32] - pACL & 22.0 & 3.0 & 3 & $63 \pm 3.4 \% / s$ & BLB & Ligament failure \\
\hline Kennedy et al.[44] & 30.8 & 2.3 & 10 & $2.083 \mathrm{~mm} / \mathrm{s}$ & LIG & \\
\hline Kennedy et al.[44] & 35.8 & 2.8 & 10 & $8.33 \mathrm{~mm} / \mathrm{s}$ & LIG & \\
\hline Paschos et al.[18] * & 42.7 & 18.5 & 10 & $1.5 \mathrm{~mm} / \mathrm{s}$ & BLB & Ligament \& insertion site \\
\hline \multicolumn{7}{|c|}{ POSTERIOR CRUCIATE LIGAMENT } \\
\hline Butler et al.[45] - donor 1 & 14.6 & 4.6 & 3 & $100 \% / s$ & BLB & Ligament failure \\
\hline Butler et al. [45] - donor 2 & 14.0 & 2.4 & 2 & $100 \% / s$ & BLB & Ligament failure \\
\hline Butler et al. [45] - donor 3 & 18.9 & 2.9 & 3 & $100 \% / s$ & BLB & Ligament failure \\
\hline Race \& Amis[46] - aPCL & 18.0 & 5.3 & 7 & $50 \% / s$ & BLB & \\
\hline Race \& Amis[46] - pPCL & 19.5 & 5.4 & 10 & $50 \% / s$ & BLB & \\
\hline Van Dommelen et al. [32] - aPCL & 18.0 & 2.3 & 2 & $45 \pm 5.7 \% / s$ & BLB & Ligament failure \\
\hline Van Dommelen et al. [32] - pPCL & 14.0 & 1.4 & 3 & $49 \pm 5.3 \% / s$ & BLB & Ligament failure \\
\hline Kennedy et al.[44] & 28.3 & 1.9 & 10 & $2.083 \mathrm{~mm} / \mathrm{s}$ & LIG & \\
\hline Kennedy et al.[44] & 24.2 & 2.1 & 10 & $8.33 \mathrm{~mm} / \mathrm{s}$ & LIG & \\
\hline \multicolumn{7}{|c|}{ MEDIAL COLLATERAL LIGAMENT } \\
\hline Kerrigan et al.[29] * & 11.5 & 5.3 & 3 & $1205 \pm 306 \% / s$ & BLB & Ligament failure \\
\hline Kerrigan et al.[29] * & 20.3 & 3.9 & 3 & $1.78 \pm 0.35 \% / \mathrm{s}$ & BLB & Ligament failure \\
\hline Kennedy et al. [44] & 24.3 & 1.3 & 10 & $8.33 \mathrm{~mm} / \mathrm{s}$ & LIG & \\
\hline Kennedy et al. [44] & 23.0 & 2.4 & 10 & $2.083 \mathrm{~mm} / \mathrm{s}$ & LIG & \\
\hline Quapp \& Weiss[41] & 17.1 & 1.5 & 9 & $1 \% / \mathrm{s}$ & LIG & \\
\hline Smeets et al.[30] * & 22.9 & 2.5 & 12 & $2 \% / s$ & LIG & \\
\hline \multicolumn{7}{|c|}{ LATERAL COLLATERAL LIGAMENT } \\
\hline Butler et al. [45] - donor 1 & 10.5 & 2.5 & 2 & $100 \% / s$ & BLB & Ligament failure \\
\hline Butler et al. [45] - donor 2 & 12.7 & 0.9 & 2 & $100 \% / s$ & BLB & Ligament failure \\
\hline Butler et al. [45] - donor 3 & 16.7 & 3.2 & 2 & $100 \% / s$ & BLB & Ligament failure \\
\hline Kerrigan et al.[29] * & 10.5 & 4.6 & 3 & $1908 \% / s$ & BLB & Ligament failure \\
\hline LaPrade et al.[47] & 16.0 & 5.0 & 8 & $100 \% / s$ & BLB & Ligament failure \\
\hline Wilson et al.[31] * & 12.5 & 2.8 & 9 & $20 \% / s$ & BLB & Ligament \& insertion site \\
\hline Smeets et al.[30] * & 41.0 & 9.9 & 11 & $2 \% / s$ & LIG & \\
\hline Sugita \& Amis[48] & 16.1 & 2.5 & 9 & $3.33 \mathrm{~mm} / \mathrm{s}$ & BLB & \\
\hline Van Dommelen et al.[32] & 15.0 & 2.9 & 4 & $\leq 0.001 \% / s$ & BLB & Ligament failure \\
\hline Van Dommelen et al.[32] & 20.0 & 5.5 & 6 & $0.04 \pm 0.009 \% / \mathrm{s}$ & BLB & Ligament failure \\
\hline
\end{tabular}




\section{Categorisation of dataset}

The injury risk functions were generated based on whether the experiments were conducted on Bone-Ligament-Bone (BLB) specimens or on dissected Ligament samples (LIG), as the two specimen types differ in which of the failure mechanisms they employ. To act for the viscoelastic characteristics of the ligaments[21], the studies were further categorised into two subgroups, depending on whether they conducted the tensile test using strain rates below (labelled "static") or equal and above (labelled "dynamic") $100 \%$ /s. IRFs were generated for sample sizes of at least 10 failure strains, Table 2 gives an overview of their characteristics and Figure 1 illustrates the construction procedure of the IRFs.

TABLE 2. Nine injury risk functions (IRFs) were generated representing either Bone-Ligament-Bone (BLB) specimens or dissected Ligament samples (LIG), studied in a tensile rate either below ("static") or equal and above ("dynamic") 100\%/s. The IRFs were composed of either virtually generated values, specimen-specific values, or a mix of the two.

\begin{tabular}{|c|c|c|c|c|}
\hline LIGAMENT & $\begin{array}{c}\text { RATE } \\
\text { (DYN/STATIC) }\end{array}$ & $\begin{array}{c}\text { SPECIMEN } \\
\text { (BLB/LIG) }\end{array}$ & $\begin{array}{l}\text { FAILURE STRAIN } \\
\text { VALUES } \\
\text { (Virtual/ Specimen- } \\
\text { specific/Mix) }\end{array}$ & SAMPLE SIZE \\
\hline $\mathrm{ACL}$ & DYNAMIC & BLB & VIRTUAL & 47 \\
\hline $\mathrm{ACL}$ & STATIC & BLB & SPECIMEN-SPECIFIC & 10 \\
\hline $\mathrm{ACL}$ & STATIC & LIG & VIRTUAL & 20 \\
\hline PCL & DYNAMIC & BLB & VIRTUAL & 30 \\
\hline PCL & STATIC & LIG & VIRTUAL & 20 \\
\hline MCL & STATIC & LIG & MIX & 41 \\
\hline LCL & DYNAMIC & BLB & MIX & 26 \\
\hline LCL & STATIC & BLB & VIRTUAL & 19 \\
\hline LCL & STATIC & LIG & SPECIMEN-SPECIFIC & 11 \\
\hline
\end{tabular}


Table 1

Ligament studies
Step 1

1.1 Generating $N_{i}$ virtual values based on mean $_{i} \pm S D_{i}$

1.2 All virtual values and specimen-specific values assembled to one dataset

Step 2

Empirical cumulative distribution function (ECDF)

Step 3

3.1 Five groups of ECDF generations: $20,50,100,500,1,000$ generations.

3.2 Five mean-ECDF, one from each group

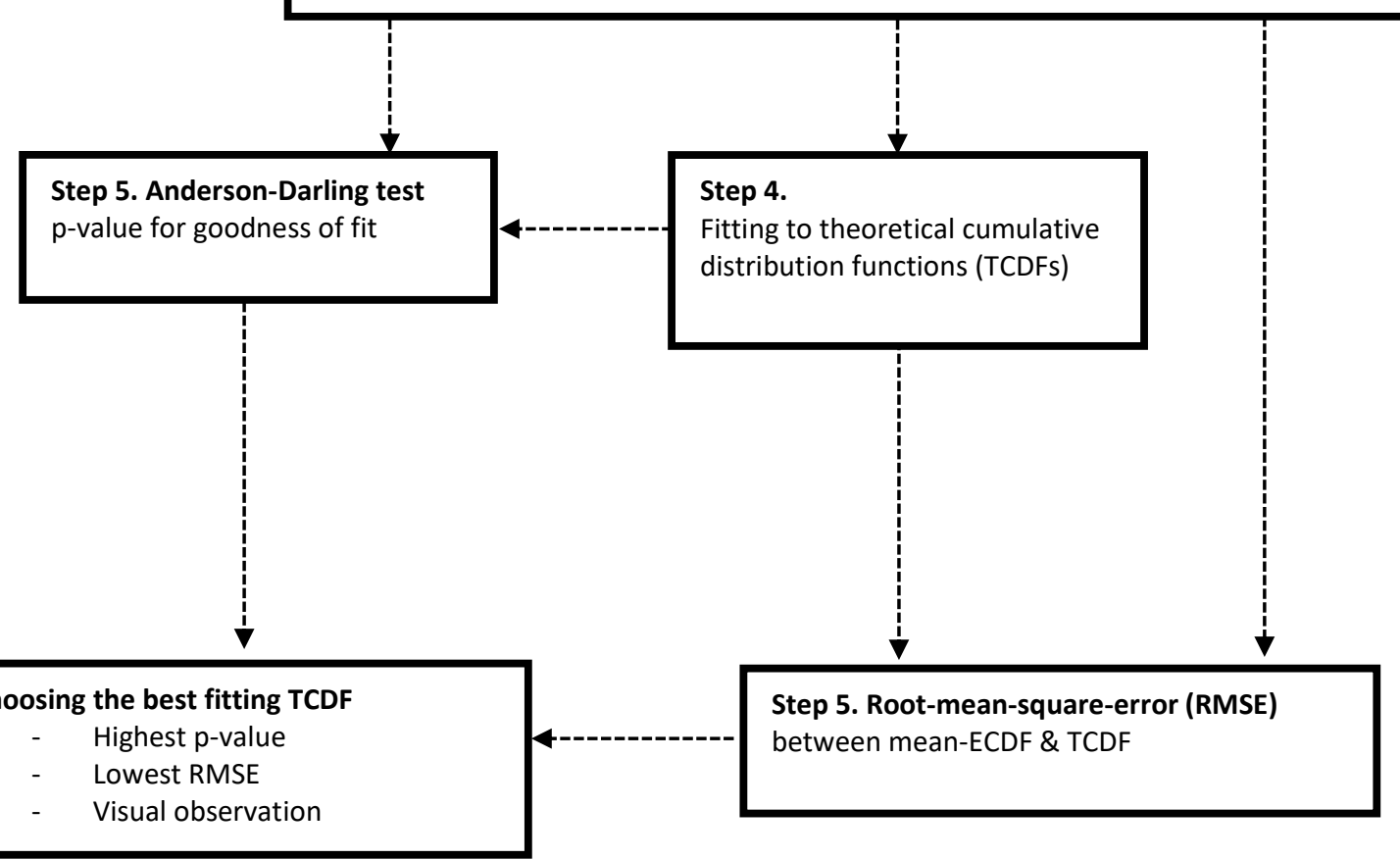

FIGURE 1. The process of constructing the injury risk functions. Experimental values were statistically generated based on studies of mean $\pm S D$ that did not provide specimen specific failure strain results (Step 1). The virtual values of all studies were thereafter assembled with the provided specimen specific results to collectively represent the dataset for one risk function (Step 2). Five groups composed of 20-1,000 generations of ECDFs were generated with five corresponding mean-ECDF's calculated representing each group (Step 3). Each mean-ECDF was tested against various theoretical distributions, and their corresponding TCDF were generated (Step 4). The best fitting TCDF was chosen based on the theoretical distribution's goodness of fit using the Anderson-Darling test, on the root-mean-square error (RMSE) between the mean-ECDF and on the TCDF and visual observations (Step 5). 


\section{Generating virtual values}

The failure strains used for the generation of virtual values (Table 1) were assumed to be normally distributed, being presented as a mean and SD. All strains were converted to Green-Lagrange strain $(\varepsilon)$, Eq. (1) and Box-Müller basic transform[34] was adopted for the generation of normally distributed virtual values, Eq. (2):

$$
\begin{aligned}
& \varepsilon=\frac{1}{2}\left(\lambda^{2}-1\right) \\
& Z=\sqrt{-2 \ln \left(U_{1}\right)} * \cos \left(2 \pi U_{2}\right) \\
& X_{\text {virtual }}=Z * \varepsilon_{S D i}+\varepsilon_{M E A N i}
\end{aligned}
$$

where $\lambda$ is the stretch ratio. $U_{1}$ and $U_{2}$ are two series of independent random variables, uniformly distributed in the interval $[0,1]$ and corresponding to each study's sample size $N$, Table $1 . Z$ is a set with the resulting independent random variables having a normal distribution and a mean value at zero \pm one unit SD, which was then shifted to match each study's mean failure strains and SD, Eq. (3). Conclusively, $X_{\text {virtual }}$ is a collection of $N$ statistically estimated failure strains, corresponding to the study's $\varepsilon_{M E A N i}$ and $\varepsilon_{S D i}$. All $\mathrm{X}_{\mathrm{virtual}}$ from each study (including the specimen-specific results if provided) were assembled in one dataset to derive one risk function.

\section{Constructing injury risk functions}

As the values in $X_{\text {virtual }}$ were randomly generated failure strains within the range of every $\varepsilon_{M E A N i}$ and $\varepsilon_{S D i}$, the robustness of the method was evaluated by generating groups of 20 , 50, 100, 500 and 1,000 Empirical Cumulative Distribution Functions (ECDFs) for each ligament. The analysis was based on calculated mean-ECDFs representing each group of ECDF generations with respect to the injury risk. Theoretical (parametric) distributions commonly used within survival analysis[35] were fitted against the mean-ECDF of all five groups by using the MATLAB function "fitdist", and the goodness of fit was evaluated with the Anderson-Darling test[36] (AD-test). The best fitting probability distribution function was chosen to derive the cumulative distribution function, to define the risk of failure based on strain. Theoretical Cumulative Distribution Functions (TCDFs) were chosen to formulate each ligaments injury risk function. The evaluation was based on: (1) the largest $p$-values from the AD-test; (2) the lowest Root-Mean-Square Error (RMSE) between the mean-ECDF and each distribution's corresponding TCDF, and; (3) visual observation of the plotted curves (Figure 1). The visual observation aimed to control for good fit primarily for the lower risk levels, as they are of most relevance in injury evaluation. The parameters in the cumulative distribution function of the chosen theoretical distribution were defined based on the smallest confidence interval between the five generation groups. 
Student's T-Test was used to evaluate the influence of strain rate on the failure threshold if the BLB IRF derived for static and dynamic rates, namely ACL-dynamic-BLB vs. ACL-static-BLB and LCL-dynamic-BLB vs. LCL-static-BLB. The null hypothesis was rejected for $p$-values $\leq 0.05$ - stating a statistical strain rate dependency of the datasets.

\section{RESULTS}

Fourteen publications met the inclusion criteria for the generation of nine IRFs. Of the tested distributions, the Log-Logistic and Weibull showed the best fit to the empirical dataset. Table 3 summarises the resulting $p$-values and RMSE for the chosen generation group of the best fitting distribution, most ranging above 0.9 and between $2.3-4.7 \%$, respectively.

TABLE 3. Log-logistic and Weibull shape and scale parameters for the nine IRFs representing the cruciate (ACL and PCL) and collateral (MCL and LCL) ligaments. The $95 \%$ confidence intervals are presented within brackets. Resulting $p$-value for the goodness of fit in the Anderson-Darling test and the Root-Mean-Square-Error (RMSE) is given for the best fitting distribution of the chosen generation group.

\begin{tabular}{|c|c|c|c|c|c|c|}
\hline $\begin{array}{l}\text { Injury risk } \\
\text { function }\end{array}$ & Distribution & $\begin{array}{c}\text { Scale } \\
\text { parameter, } \alpha\end{array}$ & $\begin{array}{c}\text { Shape } \\
\text { parameter, } \beta\end{array}$ & $\mathrm{p}$-value & $\begin{array}{c}\text { RMSE } \\
{[\%]}\end{array}$ & $\begin{array}{c}\text { Generation } \\
\text { group }\end{array}$ \\
\hline ACL DYNAMIC BLB & Log-Logistic & $\begin{array}{c}26.23 \\
(22.98-29.94)\end{array}$ & $\begin{array}{c}3.88 \\
(3.05-4.94)\end{array}$ & 0.999 & 3.58 & 500 \\
\hline ACL STATIC BLB & Log-Logistic & $\begin{array}{c}48.00 \\
(34.88-66.05)\end{array}$ & $\begin{array}{c}3.43 \\
(2.06-5.70)\end{array}$ & 0.995 & 6.93 & - \\
\hline ACL STATIC LIG & Log-Logistic & $\begin{array}{c}38.64 \\
(36.78-40.59)\end{array}$ & $\begin{array}{c}15.85 \\
(11.11-22.61)\end{array}$ & 0.992 & 4.29 & 100 \\
\hline PCL DYNAMIC BLB & Log-Logistic & $\begin{array}{c}18.62 \\
(16.88-20.54)\end{array}$ & $\begin{array}{c}6.39 \\
(4.76-8.59)\end{array}$ & 0.999 & 2.33 & 500 \\
\hline PCL STATIC LIG & Weibull & $\begin{array}{c}31.15 \\
(29.83-32.53)\end{array}$ & $\begin{array}{c}10.68 \\
(7.58-15.05)\end{array}$ & 0.995 & 4.68 & 500 \\
\hline MCL STATIC LIG & Weibull & $\begin{array}{c}26.10 \\
(24.91-7.34)\end{array}$ & $\begin{array}{c}7.19 \\
(5.60-9.23)\end{array}$ & 0.955 & 3.68 & 100 \\
\hline LCL DYNAMIC BLB & Log-Logistic & $\begin{array}{c}13.90 \\
(12.40-15.59)\end{array}$ & $\begin{array}{c}5.65 \\
(4.11-7.78)\end{array}$ & 0.999 & 2.59 & 500 \\
\hline LCL STATIC BLB & Log-Logistic & $\begin{array}{c}18.12 \\
(16.41-20.01)\end{array}$ & $\begin{array}{c}7.90 \\
(5.43-11.48)\end{array}$ & 1 & 2.86 & 100 \\
\hline LCL STATIC LIG & Log-Logistic & $\begin{array}{c}40.21 \\
(35.47-45.58)\end{array}$ & $\begin{array}{c}8.58 \\
(5.11-14.42)\end{array}$ & 0.971 & 10.2 & - \\
\hline
\end{tabular}


One $\mathrm{MCL}$ injury risk function was generated for the static rate only due to the insufficiently large dynamic dataset meeting the inclusion criteria. The Weibull distribution was selected to represent the MCL-static-LIG IRF, having both the statistical results ( $p$-value $=0.96$, $\mathrm{RMSE}=3.7 \%$ ) and the visual observation confirming the fit between the two clusters of the failure strains at the lower end of the ECDF. All ACL and PCL IRFs had slightly higher p-values and/or lower RMSE for the Gamma or Log-Normal distributions, compared to the chosen distribution (Table B1, Appendix B). However, the visual observations found the differences in the fit to be prominent and mainly located in the upper end of all the IRFs (above $60 \%$ of risk), whereas the lower end fitted equally well or better for the Log-logistic or Weibull distributions. As the lower end of an IRF is more applicable for injury prevention, the selected two distributions were chosen in favour for the simplicity of their IRFs'. The IRF of Weibull and Log-logistic distribution are expressed in Eq. (4) and Eq, (5) and visualised in Figure 2. Table 3 presents the resulting parameters for the chosen group of ECDF generations.

$$
\begin{array}{ll}
\text { Weibull CDF: } & F(\varepsilon)=1-e^{-\left(\frac{\varepsilon}{\alpha}\right)^{\beta}} \\
\text { Log-Logistic CDF: } & F(\varepsilon)=\frac{\varepsilon^{\beta}}{\varepsilon^{\beta}+\alpha^{\beta}}
\end{array}
$$

where $\varepsilon$ is the Green-Lagrange strain, $\alpha$ the scale parameter and $\beta$ the shape parameter.

Student's T-test analysis confirmed a statistical strain rate dependency between ACLdynamic-BLB and ACL-static-BLB risk functions ( $p<0.001$ ) and between LCL-dynamic-BLB and LCL-static-BLB ( $p=0.004)$. Results from Wilson et al.[31], who conducted LCL tensile tests at approximately $20 \% / \mathrm{s}$ strain rate, were included in the dynamic rate group as the failure strains showed statistical strain rate dependency to the LCL-static-BLB dataset $(p=0.001)$ and no statistical rate dependency to the dynamic dataset $(p=0.173)$. The rate dependency was also confirmed $(p=0.024)$ between the dynamic and static BLB datasets with Wilson et al.[31] excluded, assuring that any rate dependency between them is not driven by Wilson et al.[31]. 
bioRxiv preprint doi: https://doi.org/10.1101/2021.07.30.454445; this version posted August $1,2021$. The copyright holder for this preprint (which was not certified by peer review) is the author/funder. All rights reserved. No reuse allowed without permission.

Original research

Injury risk functions for the four primary knee ligaments

Jiota Nusia

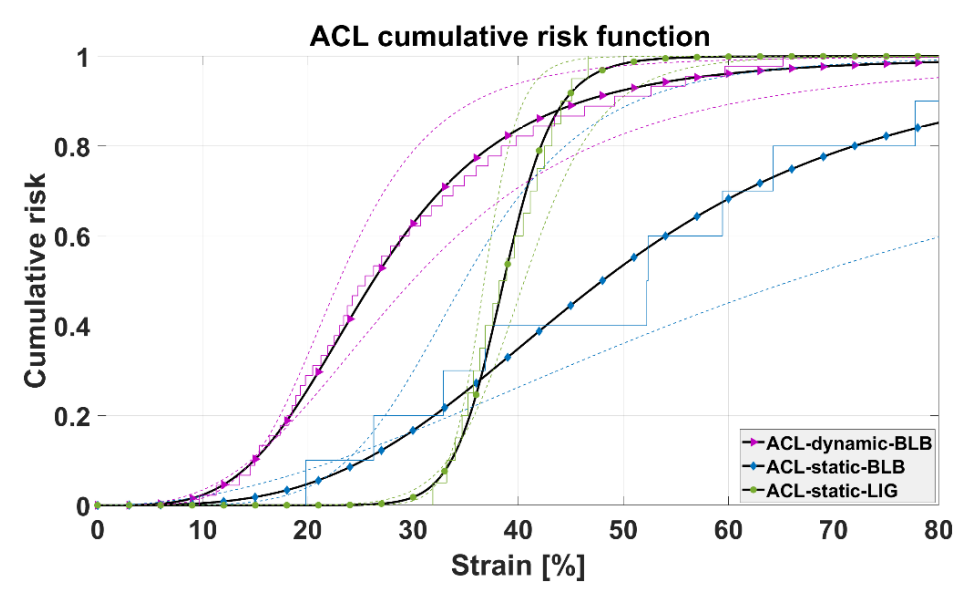

Figure 2.A Anterior Cruciate Ligament injury risk functions.

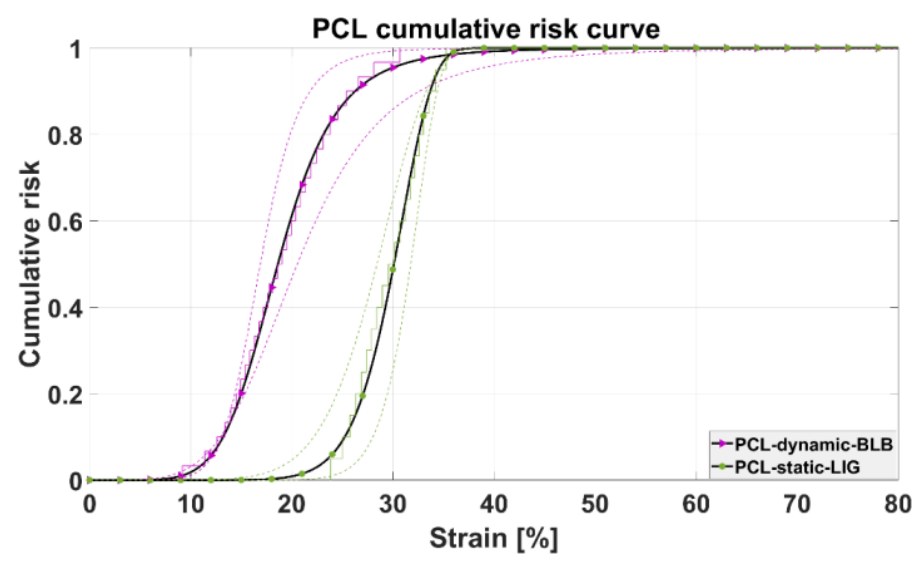

Figure 2.C Posterior Cruciate Ligament injury risk functions.

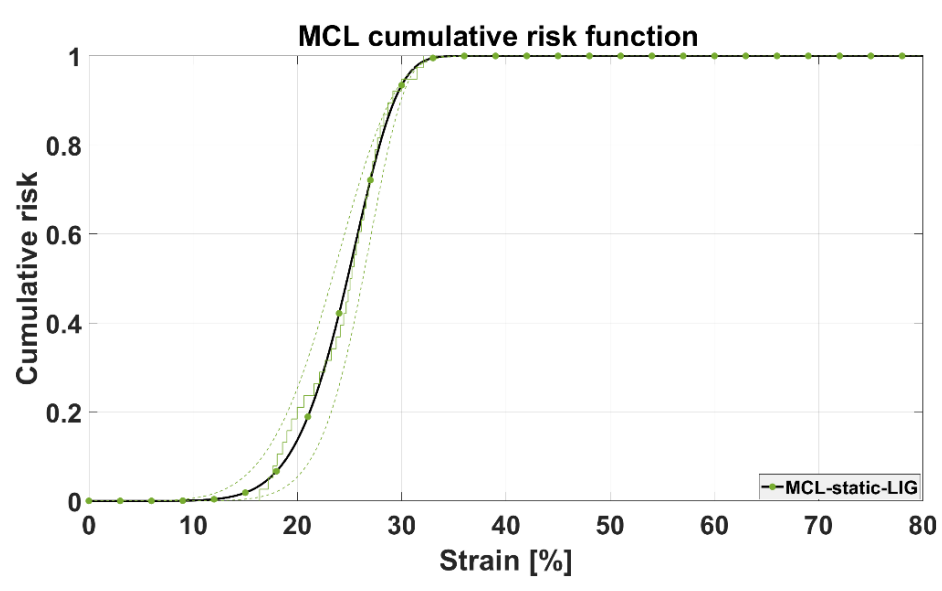

Figure 2.B Medial Collateral Ligament injury risk function.

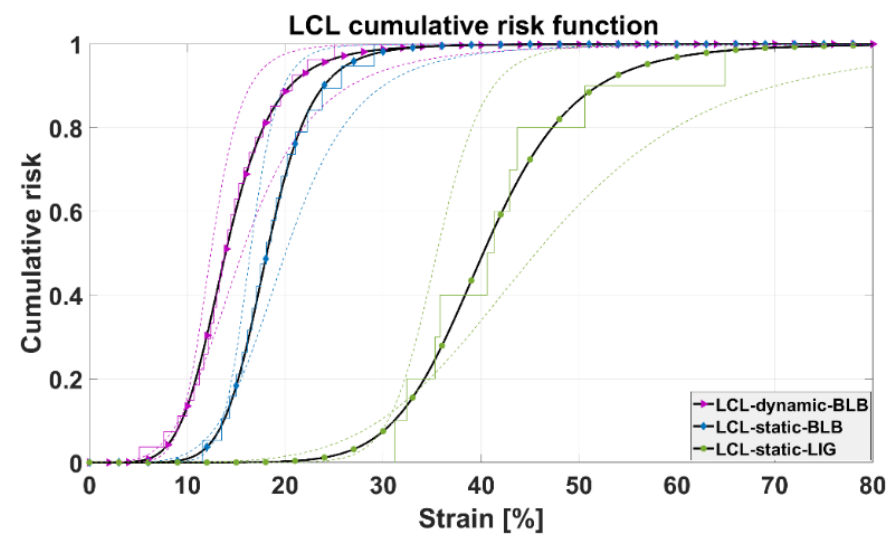

Figure 2.D Lateral Collateral Ligament injury risk functions.

Figure 2. Nine cumulative injury risk functions (IRFs) with $95 \%$ confidence intervals (dotted lines) generated from corresponding mean-ECDF. Derived from failure strains of PMHS ACL, PCL, MCL and LCL specimens, the IRFs are representing either bone-ligament-bone (BLB) or dissected ligament preparations (LIG), tested in either dynamic or static rate. One experimental datapoint in the ACL-static-BLB mean-ECDF reached $112 \%$ failure strain and is therefore not visualised in Figure 2.A. 


\section{DISCUSSION}

This study provides currently lacking risk functions for the four primary knee ligaments and offers new possibilities for injury prevention in sports or traffic. Nine injury risk functions were derived based on mean failure tensile strains conducted on PMHS ACL, PCL, MCL and $\mathrm{LCL}$ specimens. With the exception of $\mathrm{MCL}$, all ligaments have at least one IRF representing either BLB or LIG specimens tested in either the dynamic or static rate. Dynamic IRF was not derived for $M C L$ due to an insufficient number of studies meeting the inclusion criteria.

\section{The cruciate ligaments}

Most studies conducting tensile failure test on ACL and PCL, Table A1 in Appendix A, used BLB specimen preparations. Opposed to the PCL studies, several ACL studies[16-18, 37-40] conducted the testing on the whole ligament, denoted Femur - ACL - Tibia - Complex (FATC); i.e., not separating the ligament into anterior and posterior bundles. The FATC results used in the current study applied the load along the $A C L$ axis[17, 18, 37]. However, as the two bundles of the ACL vary in orientation inside the knee joint, loading the ligament in the longitudinal direction along both bundles was challenging[38]. Paschos et al.[18] defined three different failure patterns of the $A C L$, based on the failure sequences of the bundles. Observing double peaks in the force-elongation graphs, the Paschos et al.[18] study demonstrated the role of $A C L$ as a multifiber ligament, by showing that the two bundles did not rupture simultaneously during loading. Woo et al.[38] further observed that the structural properties and the failure modes (bone avulsion, ligament attachment site and mid-substance failure) in the FATC were affected depending on the tensile load alignment along the ligament. The two knee orientations tested by Woo et al. [38] showed both a difference in load uptake by the whole ligament, as well as uneven load distribution within the $A C L$, indicating that $A C L$ failure is sensitive to knee orientation during uniaxial tensile tests.

Observing that all the FATC studies used in the current study present the largest failure strains compared to the other ACL studies (Table 1), there is reason to suspect an interaction between the two bundles, compensating each other by picking up the load during failure. To control for this issue, concerning both cruciate ligaments, future experiments are suggested to measure the distribution of the tensile load between the posterior and anterior bundles.

\section{The collateral ligaments}

The LCL IRFs showed a distinct separation between the two IRFs representing BLB specimens and the IRF for dissected ligaments. The strain at mean risk of failure is approximately double the magnitude of the LCL-static-LIG compared to LCL-static-BLB. Similar proportions were observed by Robinson et al.[19], comparing MCL failure loads between BLB complexes and dissected ligaments. The two static ACL IRFs did, however, not show this correlation as 
the ACL-static-LIG demonstrated higher injury risks at lower failure strains compared to the ACL-static-BLB. Although no conclusions can be drawn from the above observations, it is possible that failure at attachment sites might occur prior to mid-substance failures, at least for the collateral ligaments.

The MCL IRF showed a statistically good fit with the MCL dataset, however, observing the mean-ECDF in Figure $2 \mathrm{~B}$, the dataset appears to not align with the expected strain behaviour of the tissue. The "bump" on the lower end of the mean-ECDF caused a modest fitting of the MCL IRF and increased the RMSE value, which is presumably induced by the failure strains reported by Quapp \& Weiss[41]. Interpretating their analysis of the behaviour of the ligaments at time of failure, it is possible that failure was defined at the time a ligament visibly entered the yield point, which would explain the lower failure strains in their study compared to the other studies.

\section{Failure mechanisms and tensile rate}

The defined tensile rate in most articles refers to the applied actuator displacement, not the resulting ligament strain rate. The current study has assumed homogeneity of the ligaments in the construction of the IRFs. Applied to the dissected ligament specimens, the displacement rate of the attachment grips has been assumed to correspond to the ligaments actual strain rate. However, the same assumption is not obvious for the BLB components. As these specimens are a complex mix of bone and ligament, an additional variety of failure modes comes with including the ligament attachments in the test setup. The flaw of such simplification can be exemplified with ligament failures occurring at one attachment site and rarely in both of a BLB complex, suggesting that the strains vary across a ligament during uniaxial loading[14, 18, 19, 42].

Nevertheless, studies experimenting on dissected ligaments exclude the insertion site failure mode by taking the ligament out of its environmental context. However, on the other hand, they gain in precision by distinctively addressing only the mid-ligament failures. BLB complexes address both failure modes although the challenge of linking the failure strain to a specific injury mechanism increases. Some studies suggest that failure at the attachment sites occur prior to mid-ligament failure[17, 19]. Other studies indicate rate dependence of the failure modes $[15,32]$ which supports the requirement of local failure strains to address injury mechanisms in future studies.

As the literature in the current study measured neither local strain rate nor local failure strains, with addition that the two specimen types address a variety of failure modes, the generated IRFs of BLB and LIG should not be compared between the two specimen preparations. Local failure strains of the ligaments are required to advance the IRFs with specimen-specific results and expanding the local failure strain datasets would facilitate addressing covariates that might affect the material properties of ligaments, such as age and gender[14, 17, 21, 37, 38, 43]. 


\section{Recommendations}

The IRFs developed in this study are, to the best of the authors knowledge, the first knee ligament injury predicting tool based on PMHSs which can be used for biomechanically optimizing knee injury prevention measures or for evaluating their effectiveness. The dynamic IRFs are of particular use in injury prediction of knee ligaments, as most (low- and high-energy) accidents are not likely to cause ligament loading in static rates. Hence, a dynamic IRF representing MCL is needed for injury prediction of higher loading rates. Although both collateral ligaments have a similar restraining function of the knee joint, enough literature has not been found supporting that the structural properties in the MCL and LCL ligaments are similar in the dynamic rate. A larger set of dynamic MCL datapoints are needed before IRFs for this ligament can be provided. Additionally, for a more refined arrangement of the dynamic loading rate experiments, future experiments must measure and provide local strain rates of the ligaments and not only the applied actuator rates, especially important for the BLB specimens.

\section{SUMMARY AND CONCLUSION}

- This study provides currently lacking risk functions for the four primary knee ligaments and offers new possibilities for injury prevention in sports or traffic.

- Developed from tensile failure strains of PMHS specimens; ACL, PCL and LCL were each represented by at least one IRF of dynamic and static tensile rate, respectively. Only limited literature of $\mathrm{MCL}$ in dynamic rates met the inclusion criteria, hence only one IRF for static rates was generated.

- Depending on whether the IRFs are based on bone-ligament-bone or dissected ligament preparations, they either address both mid-ligament and attachment site failure modes, or the mid-ligament exclusively, and should be used accordingly. 
Contributorship JN executed the study in terms of planning, data collection, result generation, analysis and writing the manuscript. SK, RS and JK conceptualised the study method and research objectives with assistance from JN and J-CX. J-CX contributed to the analysis. The result generation and analysis were supervised by SK and assisted by J-CX and SK. All authors reviewed the manuscript and approved the submitted version.

Funding The development of the study and the writing of the manuscript for scientific publication was funded by the VIRTUAL (Open Access Virtual Testing Protocols for Enhances Road User Safety) project, which in turn received funding from the European Union Horizon 2020 Research and Innovation Programme under Grant Agreement No768960. The funder had no role in the study design, data collection, analysis or writing of the report.

Acknowledgements The authors would like to thank Elisabeth Agar for the support with the language review. 


\section{REFERENCE LIST}

1 Schlumberger $M$, Schuster $P$, Eichinger $M$, et al. Posterior cruciate ligament lesions are mainly present as combined lesions even in sports injuries. Knee Surg Sports Traumatol Arthrosc. 2020;28(7):2091-2098. doi:10.1007/s00167-020-05919-4

2 Nicolini AP, de Carvalho RT, Matsuda MM, et al. Common injuries in athletes' knee: experience of a specialized center. Acta Ortop Bras. 2014;22(3):127-131. doi:10.1590/1413-78522014220300475.

3 Owesen C, Røtterud JH, Engebretsen L, et al. Effect of Activity at Time of Injury and Concomitant Ligament Injuries on Patient-Reported Outcome After Posterior Cruciate Ligament Reconstruction. Orthop J Sports Med. 2018;6(12):2325967118817297. Published 2018 Dec 28. doi:10.1177/2325967118817297

$4 \quad$ The Swedish National Knee Ligament Registry. Annual Report 2019. https://www.aclregister.nu/media/uploads/Annual\%20reports/a\%CC\%8Arsrapport kors band 2019 eng 040720.pdf (accessed 17 July 2021)

5 Prentice HA, Lind M, Mouton C, et al. Patient demographic and surgical characteristics in anterior cruciate ligament reconstruction: a description of registries from six countries. Br J Sports Med. 2018;52(11):716-722. doi:10.1136/bjsports-2017-098674

6 Sanders TL, Pareek A, Barrett IJ, et al. Incidence and long-term follow-up of isolated posterior cruciate ligament tears. Knee Surg Sports Traumatol Arthrosc. 2017a;25(10):3017-3023. doi:10.1007/s00167-016-4052-y

7 Sanders TL, Pareek A, Kremers HM, et al. Long-term follow-up of isolated ACL tears treated without ligament reconstruction. Knee Surg Sports Traumatol Arthrosc. 2017b;25(2):493-500. doi:10.1007/s00167-016-4172-4

8 Sepúlveda F, Sánchez L, Amy E, Micheo W. Anterior Cruciate Ligament Injury: Return to Play, Function and Long-Term Considerations. Curr Sports Med Rep. 2017;16(3):172-178. doi:10.1249/JSR.0000000000000356

9 Wang $\mathrm{SH}$, Chien WC, Chung $\mathrm{CH}$, et al. Long-term results of posterior cruciate ligament tear with or without reconstruction: A nationwide, population-based cohort study. PLoS One. 2018;13(10):e0205118. Published 2018 Oct 3. doi:10.1371/journal.pone.0205118

10 Everhart JS, Du A, Chalasani R, et al. Return to Work or Sport After Multiligament Knee Injury: A Systematic Review of 21 Studies and 524 Patients. Arthroscopy. 2018;34(5):1708-1716. doi:10.1016/j.arthro.2017.12.025

11 Nwachukwu BU, Adjei J, Rauck RC, et al. How Much Do Psychological Factors Affect Lack of Return to Play After Anterior Cruciate Ligament Reconstruction? A Systematic 
Review. Orthop J Sports Med. 2019;7(5):2325967119845313. Published 2019 May 22. doi:10.1177/2325967119845313

12 Filbay SR, Culvenor AG, Ackerman IN et al. Quality of life in anterior cruciate ligamentdeficient individuals: a systematic review and meta-analysis. Br J Sports Med. 2015;49(16):1033-1041. doi:10.1136/bjsports-2015-094864

13 Filbay SR, Ackerman IN, Dhupelia S, et al. Quality of Life in Symptomatic Individuals After Anterior Cruciate Ligament Reconstruction, With and Without Radiographic Knee Osteoarthritis. J Orthop Sports Phys Ther. 2018;48(5):398-408. doi:10.2519/jospt.2018.7830

14 Cho H-J, Kwak D-S. Mechanical Properties and Characteristics of the Anterolateral and Collateral Ligaments of the Knee. Appl Sci. 2020; 10(18):6266. https://doi.org/10.3390/app10186266

15 Lee $M$, Hyman W. Modeling of failure mode in knee ligaments depending on the strain rate. BMC Musculoskelet Disord. 2002;3:3. doi:10.1186/1471-2474-3-3

16 Marieswaran M, Mansoori N, Digge VK, et al. Effect of preservation methods on tensile properties of human femur-ACL-tibial complex (FATC) - a cadaveric study on male subjects. Acta Bioeng Biomech. 2018;20(4):31-42.

17 Noyes FR, Grood ES. The strength of the anterior cruciate ligament in humans and Rhesus monkeys. J Bone Joint Surg Am. 1976;58(8):1074-1082.

18 Paschos NK, Gartzonikas D, Barkoula NM, et al. Cadaveric study of anterior cruciate ligament failure patterns under uniaxial tension along the ligament. Arthroscopy. 2010;26(7):957-967. doi:10.1016/j.arthro.2009.12.013

19 Robinson JR, Bull AM, Amis AA. Structural properties of the medial collateral ligament complex of the human knee. J Biomech. 2005;38(5):1067-1074. doi:10.1016/j.jbiomech.2004.05.034

20 White EA, Patel DB, Matcuk GR, et al. Cruciate ligament avulsion fractures: anatomy, biomechanics, injury patterns, and approach to management. Emerg Radiol. 2013;20(5):429-440. doi:10.1007/s10140-013-1121-0

21 Winkelstein, B.A. (Ed.). Orthopaedic Biomechanics (1st ed.). In: Thomopoulos S, Genin GM. Tendon and Ligament Biomechanics. CRC Press. 2013:49-74.

https://doi.org/10.1201/b13733

22 Kuppa, S., Wang, J., Haffner, M., et al. Lower extremity injuries and associated injury criteria. SAE Technical Paper (2001). No. 2001-06-0160. 
23 Laituri TR, Henry S, Sullivan K, Prasad P. Derivation and theoretical assessment of a set of biomechanics-based, AIS2+ risk equations for the knee-thigh-hip complex. Stapp Car Crash J. 2006;50:97-130.

24 Prasad P, Mertz HJ, Dalmotas DJ et al. Evaluation of the field relevance of several injury risk functions. Stapp Car Crash J. 2010;54:49-72.

25 Rupp JD, Flannagan CA, Kuppa SM. Injury risk curves for the skeletal knee-thigh-hip complex for knee-impact loading. Accid Anal Prev. 2010;42(1):153-158.

doi:10.1016/j.aap.2009.07.014

26 Yoganandan N, Arun MW, Pintar FA, Banerjee A. Lower Leg Injury Reference Values and Risk Curves from Survival Analysis for Male and Female Dummies: Meta-analysis of Postmortem Human Subject Tests. Traffic Inj Prev. 2015;16 Suppl 1:S100-S107. doi:10.1080/15389588.2015.1015118

27 Weaver AA, Talton JW, Barnard RT, et al. Estimated injury risk for specific injuries and body regions in frontal motor vehicle crashes. Traffic Inj Prev. 2015;16 Suppl 1:S108S116. doi:10.1080/15389588.2015.1012664

28 Butler DL, Guan Y, Kay MD, et al. Location-dependent variations in the material properties of the anterior cruciate ligament. J Biomech. 1992;25(5):511-518. doi:10.1016/0021-9290(92)90091-e

29 Kerrigan JR, Ivarsson B, Bose D, et al. Rate-sensitive constitutive and failure properties of human collateral knee ligaments. In Proc. IRCOBI Conf 2003;177-190

30 Smeets K, Slane J, Scheys L, et al. Mechanical Analysis of Extra-Articular Knee Ligaments. Part One: Native knee ligaments. Knee. 2017;24(5):949-956.

doi:10.1016/j.knee.2017.07.013

31 Wilson WT, Deakin AH, Payne AP, et al. Comparative analysis of the structural properties of the collateral ligaments of the human knee. J Orthop Sports Phys Ther. 2012;42(4):345351. doi:10.2519/jospt.2012.3919

32 van Dommelen J, Ivarsson B, Minary Jolandan M, et al. Characterization of the RateDependent Mechanical Properties and Failure of Human Knee Ligaments. SAE Technical Paper (2005). No. 2005-01-0293. https://doi.org/10.4271/2005-01-0293

33 Rohatgi, A. (November 2020). WebPlotDigitizer: Version 4.4. https://automeris.io/WebPlotDigitizer

34 Box GEP, Muller MEA. Note on the Generation of Random Normal Deviates. The Annals of Mathematical Statistics. 1958;29(2):610-611. http://dx.doi.org/10.1214/aoms/1177706645 
35 George B, Seals S, Aban I. Survival analysis and regression models. J Nucl Cardiol. 2014;21(4):686-694. doi:10.1007/s12350-014-9908-2

36 Anderson TW, Darling DA. Asymptotic theory of certain" goodness of fit" criteria based on stochastic processes. The annals of mathematical statistics. 1952;23(2):193-212.

37 Chandrashekar N, Mansouri H, Slauterbeck J, et al. Sex-based differences in the tensile properties of the human anterior cruciate ligament. J Biomech. 2006;39(16):2943-2950. doi:10.1016/j.jbiomech.2005.10.031

38 Woo SL, Hollis JM, Adams DJ, et al. Tensile properties of the human femur-anterior cruciate ligament-tibia complex. The effects of specimen age and orientation. Am J Sports Med. 1991;19(3):217-225. doi:10.1177/036354659101900303

39 Trent PS, Walker PS, Wolf B. Ligament length patterns, strength, and rotational axes of the knee joint. Clin Orthop Relat Res. 1976;(117):263-270.

40 Jones RS, Nawana NS, Pearcy MJ, et al. Mechanical properties of the human anterior cruciate ligament. Clin Biomech (Bristol, Avon). 1995;10(7):339-344. doi:10.1016/02680033(95)98193-x

41 Quapp KM, Weiss JA. Material characterization of human medial collateral ligament. J Biomech Eng. 1998;120(6):757-763. doi:10.1115/1.2834890

42 Wijdicks CA, Ewart DT, Nuckley DJ, et al. Structural properties of the primary medial knee ligaments. Am J Sports Med. 2010;38(8):1638-1646. doi:10.1177/0363546510363465

43 Schmidt EC, Chin M, Aoyama JT, et al. Mechanical and Microstructural Properties of Native Pediatric Posterior Cruciate and Collateral Ligaments. Orthop J Sports Med. 2019;7(2):2325967118824400. Published 2019 Feb 4. doi:10.1177/2325967118824400

44 Kennedy JC, Hawkins RJ, Willis RB, et al. Tension studies of human knee ligaments. Yield point, ultimate failure, and disruption of the cruciate and tibial collateral ligaments. $J$ Bone Joint Surg Am. 1976;58(3):350-355.

45 Butler DL, Kay MD, Stouffer DC. Comparison of material properties in fascicle-bone units from human patellar tendon and knee ligaments. J Biomech. 1986;19(6):425-432. doi:10.1016/0021-9290(86)90019-9

46 Race A, Amis AA. The mechanical properties of the two bundles of the human posterior cruciate ligament. J Biomech. 1994;27(1):13-24. doi:10.1016/0021-9290(94)90028-0

47 LaPrade RF, Bollom TS, Wentorf FA, et al. Mechanical properties of the posterolateral structures of the knee. Am J Sports Med. 2005;33(9):1386-1391.

doi:10.1177/0363546504274143 
bioRxiv preprint doi: https://doi.org/10.1101/2021.07.30.454445; this version posted August 1, 2021. The copyright holder for this preprint (which was not certified by peer review) is the author/funder. All rights reserved. No reuse allowed without permission.

Original research

Injury risk functions for the four primary knee ligaments

Jiota Nusia

48 Sugita T, Amis AA. Anatomic and biomechanical study of the lateral collateral and popliteofibular ligaments. Am J Sports Med. 2001;29(4):466-472.

doi:10.1177/03635465010290041501 